\title{
SOME RECRUITMENT ASPECTS OF POPULATION PHOTOSCREENING OF AMBLYOGENIC FACTORS AT CHILDREN YOUNGER ONE YEAR
}

\begin{abstract}
Miroslav Dostálek, Jana Benešová
Hospital Litomyšl: Department of Ophthalmology, Ortoptic Section

Summary: The aim of the study was to evaluate the keystone role of paediatric general practitioners (PGPs) in our system of photoscreening of amblyogenic factors at children younger one year. The parental involvement on the participation of their children at photoscreening was also analysed. From June 2000 to February 2001 we have performed 780 photoscreening tests of children aged from 3 months to 31 months (mean age 9.7 months). The photoscreening test was voluntary. Parents was invited to visit screening center by PGP's recommendation and by offering the Invitation/information brochure. The brochure was distributed by 56 paediatric general practitioners during obligatory examinations at 5., 8. resp. 12. month of age from June to November 2000. Based on the questionnaire (return rate $89 \%$ ) we documented following data: the number of children of particular age in the care of PGPs was 2060, 1458 Invitation/information brochures was distributed by PGPs. PGPs attended for more children at particular age distributed relatively less number of brochures if compared to PGPs with lower number of relative children. The willingness to the photoscreening programe participance of parents of children belonging to PGPs attended our educational seminary exhibited independence on distance between PGP office and our department in the strong contrast to families belonging with PGPs not participating on educational programme. Our further effort on elevating the percentage of children population participation on screening must be focused on education of PGP with large number of children at particular age and on ensuring the issuing of brochures or other forms of invitation at PGPs' offices.
\end{abstract}

Key words: Photoscreening; Amblyogenic factors; Recruitment strategy; Population-based survey

\section{Introduction}

We are seemingly entering into a photoscreening era in first year of thirth millenium (16). An increasing research effort in late 90' have been directed to further development of this method for early detection of vision problem potentials, preferably an anisometropia causing ambylyopia, in infants. The American Academy of Ophthalmology states that screening is perhaps the most important factor in the ocular health of infants and children (2). The development and dissemination of knowledge about effective detection of children at risk could be found among the goals of the SAVP Programme (Strabismus, Amblyopia and Visual Processing) of the National Advisory Eye Council (U.S. Department of Health and Human Services) (26). Such an importance of screening is based on the impact of the facts like that obtained from the National Eye Institute's population-based Visual Acuity Impairment Survey pilot study, the amblyopia is the leading cause of monocular vision loss in the age group of 20-70 years (21).

An ample evidence was colected on the methodology of fotoscreening during last years. On the contrary, only a mi- nority research projects was focused on the organisational aspects accelerating effectivity of photoscreening systems. It is important to consider a wide range of issues when developing screening strategy, including the purpose of the program, how the program will be implemented, the population being served, and the potential impact on individuals. The participation by the target population is clearly a key element in the success of any mass screening programs (12). Not only in photoscreening, but similarly at other screening programs the involvement of the people invited was lower than expected. Since the effective and affordable recruitment methods are essential for achievement of screening goals $(19,22)$, these are recently studied extensively.

The majority of our knowledge related to the recruitment strategies are derived from mammography screening and programs for early detection of colorectal carcinoma. The most of analysed systems was based on the mailing of invitations to screening $(10,11,17)$. The influence of formal properties of such an invitation was analyzed. Whereas aggressiveness of message details, or a family physician's or higher authority's signature on the letter had no impact on compliance. A letter invitation for a routine mammogram 
at a specific time resuled in an rate of compliance 3-fold higher than the baseline in the city of Haifa (Israel) (20). A policy of active patient refusal was effective in increasing HIV screening among pregnant women in a large urban obstetric clinic population (24). A personal recruitment strategies (i.e.: invitation letters with or without specified appointment times, either alone or with a follow up letter or telephone call to nonattenders) were more cost-effective than public strategies (i.e. local newspaper articles, community promotion, promotion to physicians) at Australian mammography screening study. The most cost effective personal strategy was an invitation letter without specified appointment time, followed by a second letter to nonattenders (13). The provision of the program information brochure (17), and a visits of mobile screening van (1) represents other studied minor approaches. As an ineffective recruitment strategies for screening mammography appeared letterbox drops and invitations for friends (25). Neither telephone intervention (telephone outcall or advance invitation plus outcall) had a significant effect (9). Currious approach of an scratch lottery ticket for the screening attenders did not improve the compliance with the programm too (25).

The aim of our study was to evaluate some aspects of the keystone role of paediatric general practitioners (PGPs) in our system of photoscreening of eye disorders at infants under one year. The wide agreement exists there on the significant importance of the role of PGPs at the effectivity of recruitment systems. General practice and its associated primary care services are the final common pathway for the delivery of most screening programm (23) and the involvement of general practitioners in test distribution was revealed as an essential to reach satisfactory participation $(7,8,12)$. According to our knowledge of relative literature, nothing is known about the effect of incorporating the PGP to the photoscreening system focused on early identification of visual risk factors. Photoscreening programmes were generally focused on regular paedo-ophthalmology offices visitors or participants were recruited by sending an appointments according to the Community Medical Child Health register (5). We have analysed the effect of professional education of PGPs and the effect of size and location of PGPs' offices on recruitment effectivity. The parental involvement on participation of their children at photoscreening was also analysed.

\section{Matherial and Methods}

\section{Photoscreening methodology}

Photoscreening tests are performed by Ortoptic Section, Ophthalmology Department, Hospital Litomyšl, Czech Republic, since September 1999. Photoscreening is based on the excentric photorefraction principle described by Bobier and Braddick (6). Photoscreening photography are obtained to colour negative film Konica 100 ASA by camera composed of Yashica 109 multiprogram body (Kyocera Corporation, Optical Equipment Group, Tokyo, Japan),
Sonnar electric 200/2.8 lens (Carl Zeiss, Jena, Germany), custom made distance ring of axial lenght $56 \mathrm{~mm}$ and mini top electronic flash unit Unomat F 140 (Unomat GmbH \& Co. KG, Reutlingen, Germany). Photography of both eyes was obtained at dimmed room from distance of $80 \mathrm{~cm}$ (constant distance between eyes and lens aperture was justified by narrow depth of field at 2.8 f-number). Pupiles were not arteficially dilated by mydriatics. Photoscreening images were evaluated by modified method of crescend width (15). First, all the negatives images was wieved in slide viewing magnifier. Positive photography were made from suspect images. Final decision was gained by double observation of the photography of suspect image. All estimation was done by one specialist.

\section{Photoscreening organisation}

Evaluated population based photoscreening program ran at Ortoptic section, Ophthalmology Department, Litomyšl Hospital (photoscreening center) from June 2000 to February 2001. The keystone role in the children recruitment to photoscreening assumed paediatric general practitioners (PGPs) located at the area of concern (see below). Educational seminary focused on photoscreening of amblyogenic factors was organized for engaged PGPs (see below). Referral instructions were mailed to all engaged PGPs together with Invitational/informational brochures for parents (see below). PGPs were asked to offer all parents of 6-9 months old children with Invitational/informational brochures during obligatory examination and recommend them to participate on the photoscreening program. The lists of infants which parents was offered by the brochures was collected from PGPs at the end of program.

\section{Target populations}

PGPs from area of concern: 56 PGP were co-operating at photoscreening program.

Parents of infants aged 6-9 months at the time of the program: parents of 2080 infants in continuous care of engaged PGP from area of concern.

\section{Area of concern}

The program was opened for infants from Ortoptic Subdepartment, Litomyšl Hospital health care area. This represents city districts from north-eastern part of Bohemia: Brandýs nad Orlicí, Červená Voda, Česká Třebová, Hlinsko, Choceň, Jablonné nad Orlicí, Jevíčko, Králíky, Lanškroun, Letohrad, Litomyšl, Polička, Proseč, Skuteč, Svitavy, Ústí nad Orlicí, Vysoké mýto, Žamberk. The total population of the area is approximatelly 250.000 inhabitants.

\section{PGP education seminary}

Before start of the program, all PGPs were offered by the educational afternoon seminary focused on eye diseases and on photoscreening of amblyogenic factors in early infacy. 33 PGP participated on the seminary (58.9\% of PGPs engaged in the program). 


\section{Invitational/informational brochure for parents}

The eight paged Invitational/informational brochure: Visual Illnesses in Eearly Infancy was issued to serve as the invitation to particiption at the photoscreening program. Information about photoscreening procedure, methodology and evaluation as well as general information related to the most frequent eye diseases and amblyogenic factors in infancy was presented in intelligible form to parents. The information related to importance of early detection of amblyogenic factors and heredity of eye diseases (squinting, amblyopia, refractive errors) were emphasized. The same structure of information complemented by interactive FAQs option was offered at www.lit.cz/strabismus.

\section{Effectivity indices}

(1) The number of 6-9 months aged infants belonging to each engaged PGP, (2) the number of Invitaional/informational brochures issued to parents by each engaged PGP

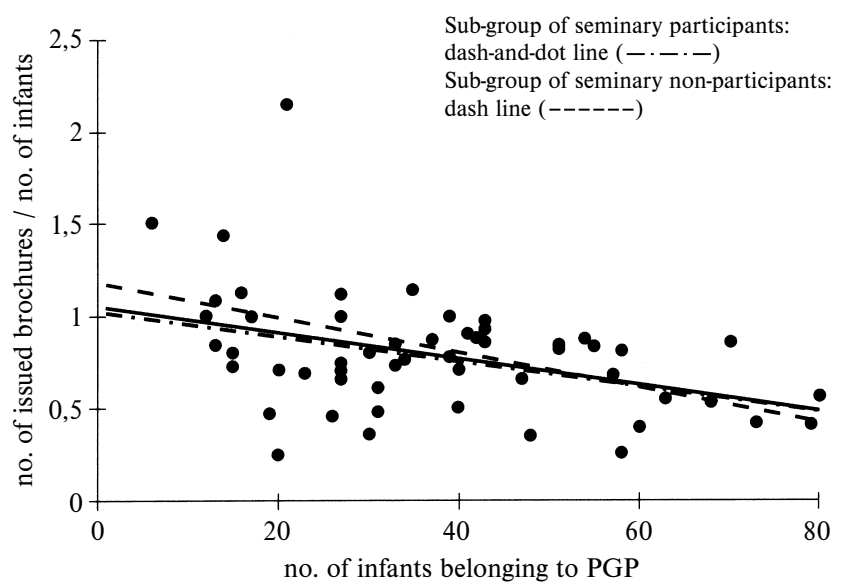

Fig. 1: Dependence of the relative number of distributed brochures (indice of PGP's involvement) on the nuber of infants belonging to the PGP

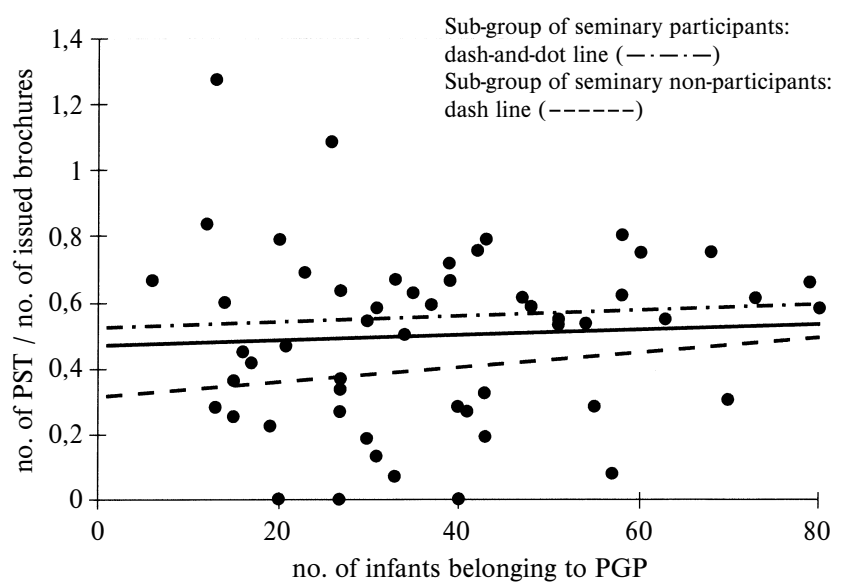

Fig. 3: Dependence of the relative number of photoscreening tests (indice of parental involvement) on the nuber of infants belonging to the PGP and (3) the number of performed photoscreening test at patients of each engaged PGP were collected from PGP's and our documantation. As a value of PGPs' involvement on the programme we used the ratio of $(2) /(1)$ and the ratio of (3)/(2) served us as a value of parental involvement.

\section{Results}

Within the period of photoscreening program 1458 Invitation/information brochures were issued by PGPs to the parents of appropriatelly aged infants. 780 of this children underwent the photoscreening procedure. It represents $53.5 \%$ of infants invited to photoscreening by issued brochures and $37.9 \%$ of all population of children at particular age. 105 infants was reffered to standard paedoophthalmologic examination on the consequence of their screening test failure. It is $13,5 \%$ suspect results of all photoscreening tests performed in the frame of the program and $5,0 \%$ of infants of concern.

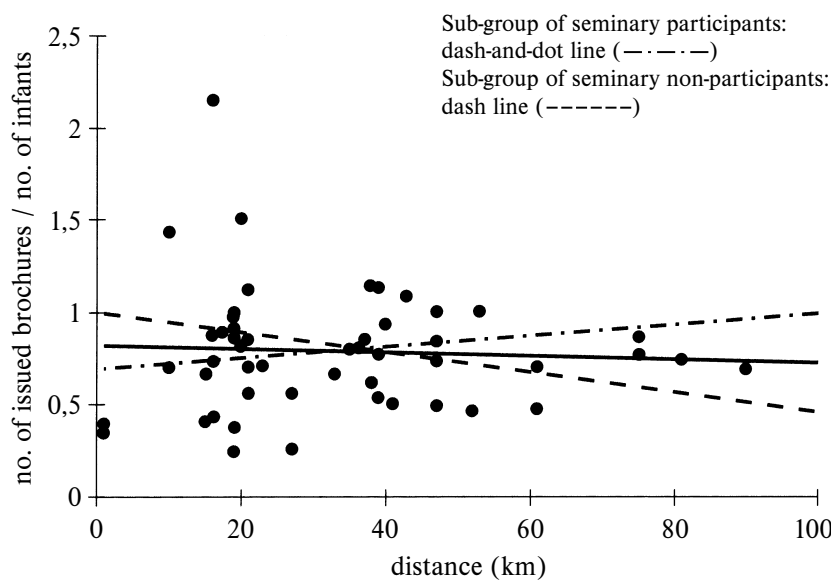

Fig. 2: Dependence of the relative number of distributed brochures (indice of PGP's involvement) on the distance between photoscreening center and the PGP's office

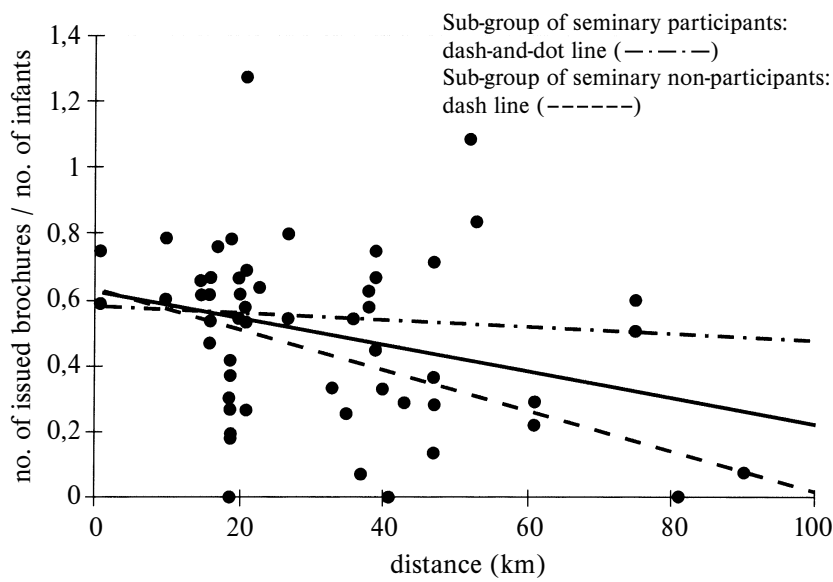

Fig. 4: Dependence of the relative number of photoscreening tests performed (indice of parental involvement) on the distance between photoscreening center and the PGP's office 
The evaluation of the influence of the number of infants of particular age in the care of each PGP to the involvement of the PGPs on the programme is illustrated by the Fig. 1. No signifficant changes were revealed at the subgroup of PGPs participating, resp. not participating at the educational seminary.

The dependence of the same parameter on the distance between the PGPs' offices and photoscreening center illustrates Fig. 2. The same regression at the group of PGPs participated resp. not participated at the education seminary is demonstrated at Fig. 2 by dash-and-dot, resp.dash lines.

The sole experience was harwested at two PGPs' offices. Regardless to our instruction to offer the Invitational/informational brochures personally by PGP, at this offices the brochures were simply laying on the table at waiting rooms. At both cases only one patient came and underwent the photoscreening test in spite of the fact that this PGPs took the care of 17, resp. 22 infants of appropriate age.

The ratio between the number of photoscreening tests performed to infants belonging to PGP and the total number brochures issued by this PGP was used as a general measure of the parental involvement on the performance of the photoscreening test at their infants. The relation of this ratio to the volume of PGPs' file of patient of particular age is presented at Fig. 3. The black line illustrates the regression on the whole group of PGPs. The interrupted lines represents the same dependece at sub-group of PGP participating (dash-and-dot line) and not-participating (dash line) on the educational seminary.

Fig. 4 represents the dependence of this parameter on the distance between PGPs' offices and photoscreening center. Dash-and-dot, resp. dash lines on Fig. 4 illustrates the same dependece at the sub-group of PGPs participating, resp. not-participating on the educational seminary.

\section{Discussion}

During the time period of our study, 1458 Information brochures was provided, 780 children underwent the photoscreening procedure. The gained attendance rate of $53.5 \%$ is comparable to analogous parameters from other studies. Attendance rate at visual screening program (based on isotropic photoscreening method) at Cambridge, UK, varies from clinic to clinic between $62 \%$ and $80 \%$, (5). In Victoria (Australia) only $55 \%$ of the population with diabetes accessed eye care services at the recommended intervals (17). The participation rates at other, mainly oncologic, types of screening (i.e. colorectal carcinoma screening, cervical carcinoma screening, breast cancer screening, etc) varies widely from $45 \%$ to $92 \%(4,10,12,14,20)$. The ratio achieved at our study is remarkably lower than those from Atkinson and Braddick's screening programme at Cambridge (5). The possible explanation can be derived from the fact that the participation rates among some demo- graphic sub-groups are substantially low (18). The overall participation rate at Haemocult screening for colorectal carcinoma performed by Herbert, et. al. (12) at county of Calvados, France, varied essentially according to the place of residence: from $65.5 \%$ in urban areas and $48.9 \%$ in intermediate areas to $27.7 \%$ in rural areas. Our helath care area could be characterised as an intermediate area.

The our recruitment strategy was based on two pillars. The first was the paediatric general practitioners involvement (PGPs' involvement) and the second was the appropriatelly aged infant parents involvement (parental involvement).

The keystone role of the personal recommendation to participate on screening by general practitioner is widely accepted as an esencial prerequisit for reaching satisfactory effectivity of screening recruitment system $(3,12)$. A significantly higher attendance rates was documented in one town that received the family physician involvement intervention compared with its matched town which received the community intervention ( $68 \%$ vs. $51 \%$ attendance rate) on the other study performed at rural communities in New South Wales, Australia (8). On the other study performed at the same region, the media/GP based campaign was associated with significant increase in attendances in all three regions (whereas the television media alone increase attendance only in one region and the media/letter based campaign in two regions respectively) (7). In the Haifa study of recruitment for mammography screening were having a health professional recommendation among the major predictors of compliance. Whereas aggressiveness of message details, or a family physician's or higher authority's signature on the letter had no impact on compliance (20). In spite of the fact that our research was not focused on the question whether the PGP recommendation attributes the attendance or not, we could support these literature data by the two ocassional obserwations. At two PGP's offices where the Invitational/informational brochures simply laiyng at waiting rooms (no PGP's recommendation) the attendance rates dropped to $6 \%$, resp. $4.5 \%$.

In our study the ratio between number of issued brochures by PGP and number of aprpriately aged children at the PGP's health care served as a measure of the PGP's involvement. Such an objective measure represents the effort, which was payed by each PGP engaged at study to provide all his/her patients by photoscreening at approppriate age.

One aspect we have studied at the behaviour of PGPs at recruitment process was the impact of number of children aged 6-9 months at practitioners regular care onto the PGP's involvement measure. There was revealed evident tendency of reduction of effort at PGPs with larger number of appropriately aged infants (see Fig. 1) at regular care. In a few cases of PGP with smaller number of respecticve patients, we registered the tendency to issue brochures even for older children (ratio above 1,0). 
Bearing the importance of PGP recommendation in mind, we studied the influence of educational and informational policy to the co-operating practitioners. For further analysis of the PGPs involvement we divided them to the sub-groups of seminary participants and non-participants. It is important that invitation for seminary participation was mailed to all PGP, so that the sub-groups mentioned above are not divided randomly and obtained diferences between both sub-groups are resulting not only from participation at seminary but could reflect a previous attitude towards visual screening. The division of the group of PGPs according to participation at educational seminary does not reveal any difference between subgroups at the relation of PGPs involvement measure and the number of patients.

On the contrary to the sub-group of PGPs non-participating on the seminary, the evident tendency of increasing the relative number of issued brochures (indice of PGPs' involvement) with increasing distance between practitioner's office to the screening centre was documented at the sub-group of seminary participants (see Fig. 2). Such a tendency is highly appreciable because it outweights the opposite trend at parental involvement as described below.

The distance between PGPs' office and screening center does not play signifficant role at measure of PGP's involvement if related to the number of 6-9 months aged infants in regular care of respective PGP.

Practical conclusions related to the first pillar (PGPs' involvement):

1) To ensure the providing the Invitation/information brochure by PGP personally.

2) To focuse the encouragement of PGPs with large number of 6-9 months aged infants to issue the Invitation/information brochures more systematically.

3) To invite PGPs from more distant offices for participation at professional education dealing with various aspects of visual screening.

The second pillar of our recruitment system was parental involvement. There is no published research focused on this aspect of recruitment strategy, according to our best knowledge. Our analysis was focused on the estimation of influence of number of 6-9 months aged infants belonging to PGP and the distance from PGP's office to photoscreening center on the parental involvement. The educational and recruitment effectivity of the Invitational/informational brochure was not a subject of our study.

The ratio of the number of photoscreening tests performed as a consequence of the invitation at issued brochure to the number of this issued Invitational/informational brochures by PGP served at our study as a measure of involvement of families belonging to respective PGP on performance of visual screening at their children.

On the contratry to the decrease of the PGPs involvement with increase of number of infants belonging to respective PGP, the parental involvement demonstrated the opposite tendency. With increase of size of the PGP's health care area, the increase of parental involvement was record- ed (compare Fig. 1 and Fig. 3). The similar steepness of the regression line was revealed in the sub-groups of parents belonging to PGPs participating resp. non-participating on the educational seminary (see dash-and-dot and dash lines at Fig. 3). Ony one difference between these two sub-groups was shift down of the regression line at sub-group of parents belonging to the non-participating practitioners. Such an observation confirms the superb importance of the form of PGPs' recommendation to participate on visual screening.

Second analysed feature of parental involvement was the influence of distance between screning center and the respective PGP's office on it. There were no records of infants' addresses obtained during photoscreening procedure. Because it is common to be registered at nearest PGP's office, the locations of respective PGPs' were considered as locations of infants homes with approppriate simplification. According to our hypothesis the willingness of families to participate at the visual screening process was the function of the distance between place of PGP's office and screening center. With increase of the distance we have recorded decrease of the measure of parental involvement (see Fig. 4.) Our observations are in good accordance to the sole findings of influence of reachability of screening center to attendance ratio. A negative impact of concerns on participation, althought only marginally significant, revealed by telephone interviews was observed among those who perceived it to be difficult to get to the health center where the breast cancer screening was provided by Health Maintenance Organisation at USA. (18). Dash-and-dot, resp. dash line at Fig. 4 represent the same relation but at the sub-groups of patients belonging to PGPs participating, resp. non-participating at the educational seminary. From comparisson of both lines, the difference at declination of the lines is visible. It could be hypothetised that PGPs participating at seminary are more effective at recommending the participation at screening, so that could outweight the negative influence of distance from place of living to the screening center. This influence of seminary participation is additive to the effect of seminary attendance to the relative number of issued brochures at more distant practitioners' offices (see dash-and-dot line at Fig. 2).

Practical conclusions related to the second pillar (parental involvement):

1) To ensure participation of PGPs from more distant offices for participation at professional education dealing with various aspects of visual screening.

\section{Conclusions}

Each of the screening centers must tailor recruitment to its individual catchment area. For intermediate (non-rural, non-purely-municipal). The keystone role of PGPs' recommendation to participate on visual screening could be ammeliorated by professional educaion preferably for practitioners from more distant offices and from offices with larger number of approppriatelly aged infants. 
This paper has been presented as a poster at the IVth Symposium on Paediatric Ophthalmology, May 2001, Bratislava, Slovak Republic, XIIIth Congress of the European Society of Ophthalmology, June 2001, Istambul, Turkey and 6th Conference of project "Zdraví, November 2001, Praha, Czech Republic.

This study was financially supported by Ministry of Health of Czech Republic (project MZ ČR Zdraví $163 / 2000)$.

\section{References}

1. Adelson P, Irwing L, Turnbull D. Evaluating the impact of a promotional campaign for screening mammography: who attends? Aust J Publ Health 1992; 16(1):66-71.

2. American Academy of Ophthalmology, Infant and Children's Eye Care A Statement by the American Academy of Ophthalmology to Select Panel for the Promotion of Child Health, San Francisco: American Academy of Ophthalmology, 1980.

3. Andreoni B, Crosta B, Lotti M et al. Flexible sigmoidoscopy as a colorectal cancer screening test in the general population: recruitment phase results of a randomized controlled trial in Lombardia, Italy. Chir Ital 2000;25(4):279-92.

4. Aro AR, de Köning HJ, Absez P, Schreck M. Psychosocial predictors offirst attendance for organised mammography screening. J Med Screen 1999;6(2):82-8.

5. Atkinson J, Braddick OJ, Durden K, Warson PG, Atkinson S. Screening for refractive errors in 6-9 month old infants by photorefraction. Br J Ophthalmol 1984;68:105-12.

6. Bobier WR, Braddick O. Eccentric photorefraction: Optical analysis and empirical measures. Am J Optom Physiol Optics 1985;62(9):614-20.

7. Byles JE, Sanson-Fischer RW, Redman S, Dickinson JA, Halpin S. Effectiveness of three community based strategies to promote screening for cervical cancer. J Med Screen 1994;1(3):150-8.

8. Clover K, Redman S, Forbes J, Sanson-Fisher R, Callaghan T. Two sequential randomized trial of community participation to recruit women for mammographic screening. Prev Med 1996;25(2):126-34.

9. Crane LA, Leakey TA, Rimer BK, Wolfe P, Woodworth MA, Warn RB. Effectiveness of a telephone outcall intervention to promote screening mammography among low-income women. Prev Med 1998; 27(5Pt2):S39-49.

10. Dorsch MM, Cheok F, Ingham HM. The effectiveness of invitations from general practitioners in recruiting women to mammographic screening. Med J Aust 1991:155(9):623-5.

11. Hagoel L, Ore L, Neter E, Shifroni G, Rennert G. The gradient in mammography screening behaviour: a lyfestile marker. Soc Sci Med 1999;48(9):1281-90.

12. Herbert C, Launoz G, Thezee Y et al. Participants' characteristics in a French colorectal cancer mass screening campain. Prev Med 1995;24(5):490-502.

13. Hurley SF, Jolley DJ, Livingston PM, Reading D, Cockburn J, Flint-Richter D Effectiveness, cost, and cost-effectiveness of recruitment strategies for a mammographic screening programm to detect breast cancer. J Natl Cancer Inst 1992; 84(11):855-63.
14. Ibbotson T, Wyke S, McEwen J, Macintyre S, Kelly M. Uptake for cervical screening in general practice: effect of practice organisation, structure and deprivation. J Med Screen 1996;3(1):35-9.

15. Kaakinen K. A simple method for screening of children with strabismus, anisometropia or ametropia by simultaneous photography of the corneal and fundu reflexes. Acta Ophthalmol (Kbl.) 1979;57:161-71.

16. LaRoche GR. Detection, prevention, and rehabilitation of amblyopia. Curr Opin Ophthalmol 2000;11(5):306-9.

17. Lee SJ, McCarty CA, Sicary $C$ et al. Recruirment methods for community-based screening for diabetic retinopathy. Ophthalmic Epidemiol 2000;7(3):209-18.

18. McBride CM, Curry SJ, Taplin S, Anderman C, Grothaus L. Exploring environmental bariers to participation in mammography screening in an HMO. Cancer Epidemiol Biomarkers Prev 1993;2(6):599-605

19. Olson KL, Chapman JA, Thurston WE, Milligan CD. Promotion of breast cancer screening in communities: a research agenda. Cancer Prev Control 1997; 1(3):213-21.

20. Ore L, Hagoel L, Shifroni G, Rennert G. Compliance with mammography screening in Israeli women: the impact of a pre-scheduled appointment and of the letter style. Isr J Med Sci 1997;33(2):103-11.

21. Report on the national Eye Institute's Visual Acuity Impairment Survey Pilot Study. Washingtn DC: Office of Biometry and Epidemilogy, National Eye Institute, National Institutes of Health. Public Health Service, Dept of Health and Human Services, 1984.

22. Rimer BK, Schildkraut JM, Lerman C, Lin TH., Audrain J. Participation in a women's breast cancer risk counselling trial. Who participates? Who declines? High Risk Breast Cancer Consorsium. Cancer 1996;77(11):2348-55.

23. Robson J. Screening in general practice and primary care. Br Med Bull 1998; 54(4):961-82.

24. Stringer E, Stringer J, Cliver S, Goldenberg R, Goepfert A. Active refusal increases human imunodeficiency virus screening in urban prenatal clinic system. Obstet Gynecol 2001;97(4Suppl1):58.

25. Turnbull D, Irwing L. Ineffective recruitment strategies for screening mammography: letterbox drops and invitations for friends. Aust J Publ Health 1992;16(1):79-81.

26. Vision Research, A National Plan: 1999-2003, A Report of the National Advisory Eye Council, U.S. Department of Health and Human Services, Washington: National Institutes of Health, NIH Publication 1998, No. 98.4120,97.

Submitted July 2002.

Accepted August 2002.

MUDr. Miroslav Dostálek, Ortoptic Section,

Department of Ophthalmology,

Hospital Litomyšl,

J. E. Purkyně 652, 57014 Litomyšl,

Czech Republic.

e-mail: dostalek@lit.cz 